\title{
Analysis of Main Components and Prospects of Natto
}

\author{
Yanchun Liu, Yanxia Han, Lingli Cao, Xiuling Wang, Shijuan Dou* \\ College of Life Sciences, Hebei Agricultural University, Baoding, China \\ Email: *dsj75@126.com
}

How to cite this paper: Liu, Y.C., Han, Y.X., Cao, L.L., Wang, X.L. and Dou, S.J. (2021) Analysis of Main Components and Prospects of Natto. Advances in Enzyme Research, 9, 1-9.

https://doi.org/10.4236/aer.2021.91001

Received: May 19, 2020

Accepted: March 21, 2021

Published: March 24, 2021

Copyright (c) 2021 by author(s) and Scientific Research Publishing Inc. This work is licensed under the Creative Commons Attribution International License (CC BY 4.0).

http://creativecommons.org/licenses/by/4.0/

(c) (i) Open Access

\begin{abstract}
The word "natto" originated from Japan, which was known as stinky bean, salt bean or silk bean in Chinese folk. Natto contains multiple functional components, including nattokinase, soybean isoflavone, $\gamma$-polyglutamic acid, vitamin $\mathrm{K}_{2}$, biogenic amines, SOD, small-molecule polypeptide, which has good preventive and curative effects for many diseases, such as cardiovascular and cerebrovascular diseases, hyperlipidemia, hypertension, menopausal symptoms and hypoimmunity. Along with the aging population in the world and China, it is urgent to improve the quality of life. It is necessary to enhance the understanding of natto-related knowledge, expand propaganda power, accept natto consciously and eat natto frequently, which is good for our health and helps our country to build a healthy and harmonious society. This review will descript the development, components, functions and prospects of natto, which help us to offer theoretical basis for promoting natto industry.
\end{abstract}

\section{Keywords}

Natto, Nattokinase, Cardiovascular and Cerebrovascular Diseases, Functional Food

\section{Introduction}

The word "natto" originated from Japan, which is fermented by natto Bacillus subtilis after ordinary steaming or high-pressure steaming. It has a special flavor and contains many functional components, such as nattokinase (NK), $\gamma$-polyglutamic acid, superoxide dismutase (SOD), glutathione peroxidase, soy isoflavones, saponins, angiotensin-converting enzyme inhibitors (ACEI), vitamin $\mathrm{K}_{2}$ and small molecule peptides, and so on. All of these components give natto multiple functions, including improving gastrointestinal health, dissolving blood clots, reducing blood fat [1] [2], lowering blood pressure [3], antioxida- 
tion [4], preventing stroke [5], preventing Alzheimer disease [6], preventing atherosclerosis [7], preventing calcium loss [8]. It is of great benefit to human health. Therefore, natto is known as "super healthy food". With the growing elderly population, it is very important to prevent cardiovascular and cerebrovascular diseases, which are the first killer in the world, and then improve senior citizens' healthy level and enhance the happiness index. Japan is the longest-lived country in the world, with an average age of 84 , according to WHO statistics in 2019. Natto has become a must-have for dining table. There is a popular phrase among Japanese people, which is "Eat natto every meal, live up to 99". But in our country, although natto industry has been developed for more than 20 years, natto has not been accepted by people for many reasons, one of which is the lack of good propaganda and promotion. The purpose of this paper is to make people realize the importance of natto, and accept natto consciously, eat natto frequently, and finally achieve the purpose of "everyone eats natto, healthy without trouble". Putting the healthy body and the spiritual civilization as the ultimate goal, we will push forward to create a healthy, sustainable, stable and harmonious society.

\section{The Development History and Function of Natto}

\subsection{The Development History of Natto}

Natto is made of fermented soybean by natto bacteria and similar to our traditional fermented soya beans. Fresh natto is golden in color and soft in taste. If it is picked up with chopsticks, it will have a long thread like mucus. If combined with appropriate condiments, it has a favorite flavor, deeply liked by the Japanese people and regarded as an essential flavor food. Natto has a history of 2000 years so far. There are different opinions on the origin of natto, but most people think that natto originated in China and was brought into Japan during the Tang Dynasty when the eminent monk Jianzhen traveled to Japan to preach. After that, there was a new change of natto in Japan. At first, it was fermented by the natural bacterium Bacillus subtilis on the straw and made in the kitchen of the temple. Because the kitchen of the temple was called “納所”, the fermented soybean was called “納豆”. At that time, natto was an important source of nutrition for vegetarian monks and was the imperial nutrition for Japanese royal families, nobilities and warriors. After Meiji Restoration in Japan, natto gradually flowed out from temple and royal family to normal Japanese people. In 1980, a Japanese researcher, Dr. Hiroyuki Sumi, accomplished the famous "2:30 pm experiment" in the laboratory of the University of Chicago in the United States [9]. He found that there was an enzyme in mucus thread that could dissolve thrombus, and named nattokinase. After that, with the development of refrigeration technology, natto had changed from workshop-type production to factory-type production. In 1983, Japan formulated the industry standard of natto. In 1992, the Japanese natto festival was made up in July $10^{\text {th }}$, because of 7 representing “納” and 10 representing “豆” in Japanese. Since 1996, when Japanese government has ad- 
vocated people to eat natto, people's height and life-span have been greatly improved. Natto is regarded as "the best healthy food in the world" in Japanese book, the rarest traditional food-Natto. Recently, WHO released the latest report, World Health Statistics in 2018. In this report, nothing is more concerned than the life-span ranking list. Japanese average life-span has been the highest for 20 years, reaching 84 on average, of which the life-span of the female is 87 , and that of the male is 81 . However, the Chinese life-span is only 76 years old. In addition to Japanese unique geographic environment, it has a great matter with the Japanese always eating traditional fermented food "natto". This is the reason why Japan can become the longest-lived country in the world.

\subsection{Health Care Functions and Main Components of Natto}

In addition to its unique flavor and convenient production, natto also has a variety of nutritional and health care functions, for example, dissolving blood-clot, reducing blood pressure, anti-bacteria, anti-tumor, preventing osteoporosis, promoting gastrointestinal health, etc. Natto contains nattokinase, soybean isoflavone, $\gamma$-polyglutamic acid, vitamin $\mathrm{K}_{2}$, biogenic amines, superoxide dismutase (SOD), small-molecule polypeptide and so on. Therefore, natto is known as "super healthy food".

\subsubsection{Nattokinase}

Nattokinase (EC 3.4.21.62) is a kind of serine protease [10]. Compared with other human thrombolytic agents, including urokinase, tissue-type plasminogen activator (t-PA) and streptokinase, NK has obvious advantages, including fewer gastrointestinal side effects and better stability [11]. NK has a good effect on arterial thrombosis mediated by oxidative damage and venous thrombosis induced by inflammation. There are four main aspects of thrombolysis. First, it has a direct hydrolysis effect on cross-linked fiber thrombus, hydrolyzing fibrin into soluble small molecules. Second, NK can stimulate endothelial cells to produce endogenous t-PA, which catalyzes plasminogen into plasmin and then enhances its fibrinolytic activity. Third, NK catalyzes prourokinase into urokinase. Urokinase is not only a kind of thrombolytic agent but also a kind of plasminogen activator (PA). Fourth, NK degrades plasminogen activator inhibitor-1 (PAI-1). PAI-1 is the main factor regulating the balance of fibrinolytic system in vivo by suppressing t-PA to reduce the activation of plasminogen into plasmin. Through degrading PAI-1, NK can regulate the balance among PAI-1, t-PA, plasminogen, plasmin, fibrin protein, and improve the function of thrombolysis [2].

NK just can hydrolyze fibrin, the main substance of thrombus, and can't hydrolyze plasma fibrinogen. So, it doesn't like the traditional thrombolytic drugs which maybe cause the risk of bleeding. This advantage of NK is not possessed by other thrombolytic drugs clinically. In addition, the further clinical study found that NK also had significant inhibition of platelet aggregation and hypertension. Natto mucus contains a substance of lowering blood pressure, the inhibitor of angiotensin converting enzyme (ACE). When people eat it, their blood 
pressure will be decreased.

\subsubsection{Soybean Isoflavone}

Soybean isoflavone is a kind of non-steroidal and heterocyclic phenolic substance, which is abundant in soybean. Soybean isoflavone is similar to mammalian estrogen (17- $\beta$-estradiol) in structure, metabolizes to produce equol in the intestine. So, it is called natural plant estrogen [12]. Soybean isoflavone is also a subclass of flavonoids, which have antioxidant properties. It can sweep away free radicals, the by-product produced by cells in the normal metabolism process, and prevent the occurrence of cancer caused by the damage of free radicals to DNA [13]. Daidzein can enhance catalase activity [4]. Menopause is characterized by decreased estrogen secretion from the ovaries, which contributes to the risk of osteoporosis. Soy isoflavones may act as substitute for natural estrogen to prevent osteoporosis [14]. In conclusion, soybean isoflavones have many benefits for human health, such as preventing menopausal symptoms, breast cancer, prostate cancer, cardiovascular and cerebrovascular diseases, osteoporosis, obesity, diabetes, Alzheimer's disease, virus infection [14].

\subsection{3. $\gamma$-Polyglutamic Acid}

The health care function of natto is related to some active substances in mucus. After soybean fermented by natto bacterial, natto mucus is similar to a mixture of fructan, fructose and $\gamma$-polyglutamic acid (PGA), in which PGA is the main component of mucus. PGA is a kind of water-soluble poly amino acid produced by microbial fermentation in nature [15]. Its structure is a polymer with peptide bond formed by glutamic acid unit through $\gamma$-carboxyl and $\alpha$-amino group, in which D-glutamic acid is the majority. PGA is a long-lasting moisturizer, which can effectively increase the moisturizing function and promote skin health. Its moisturizing effect is $2-3$ times higher than that of hyaluronic acid. Natto mask products also appeared on the market. PGA also has excellent biocompatibility, biodegradability, non-toxicity and non-pollution, so it can be used as an ideal biomaterial.

\subsubsection{Vitamin $\mathrm{K}_{2}$}

After taking vitamin $\mathrm{K}_{2}$, it will first be absorbed by liver cells to promote the coagulation of normal blood. NK dissolves thrombus and promotes blood circulation, while vitamin $\mathrm{K}_{2}$ promotes blood clotting. For fermented foods rich in NK, vitamin $K_{2}$ can reduce the activity of NK. For a product with high activity of $\mathrm{NK}$, the presence of vitamin $\mathrm{K}_{2}$ may have a negative impact on the efficacy of NK [16]. But except for vitamin $K_{2}$, coagulation is a complex and comprehensive process. It needs the participation of prothrombin activator, fibrinogen activator, coagulation factor, calcium, platelet and many other substances. Any single component can't complete the process of coagulation. Under normal circumstances, vitamin $\mathrm{K}_{2}$ would not cause blood clotting even if large amount of $\mathrm{K}_{2}$ had be taken (http://j-nattokinase.org/jnka_nk_english.html). However, under special circumstances, natto or nattokinase products should not be used if the body 
has a bleeding injury, such as gastric ulcer, hemorrhoid or trauma.

In addition to the above, vitamin $\mathrm{K}_{2}$ constantly moves through the bloodstream and activates Matrix $\gamma$-Carboxyglutamic acid (GLA) Protein (MGP) which is the regulatory factor of inhibiting vascular calcification. As a result, vitamin $K_{2}$ can prevent calcium deposits in the blood vessels and so prevent arteriosclerosis from happening. Vitamin $\mathrm{K}_{2}$ can also prevent cirrhosis from developing into liver cancer. Vitamin $\mathrm{K}_{2}$ can also activate osteocalcin in bone marrow, promote the generation of bone protein, and then generate bone together with calcium to increase bone density and prevent fracture, further achieving the purpose of treatment and prevention of osteoporosis. In recent years, it has been found that postmenopausal women often have calcification of blood vessels at the same time of osteoporosis. It is believed that there may be a close relationship between them. MGP can inhibit the calcification of blood vessels and is closely related to bone metabolism [8]. In addition to soybean isoflavone, natto is also rich in vitamin $\mathrm{K}_{2}$, which provides another strong evidence for reducing or slowing down menopausal symptoms.

\subsubsection{Biogenic Amines}

Biogenic amines are low-molecular-weight organic compounds containing nitrogen, which are produced when food rots or ferments. For example, putrescine, also known as butanedione, is formed by decarboxylation of ornithine under the catalysis of amino acid decarboxylase. Spermidine is widely distributed in organisms, and is synthesized by putrescine (butylamine) and decarboxylated S-adenosylmethionine (dcSAM) under the catalysis of spermidine synthase. Spermidine and dcSAM can be converted into spermine by adding organic compounds containing $3 \mathrm{C}$ and $1 \mathrm{~N}$ under the catalysis of spermine synthase. Because putrescine, cadaverine, spermine and spermidine are very important components for living cells, biogenic amines can promote the physiological function of human body and play a very important role in regulating the synthesis of nucleic acid and protein and the stability of biological membrane. Spermidine is an inducer of autophagy mechanism, through degrading the damaged proteins to protect the cardiovascular system. Spermidine also has an anti-inflammatory effect and prevents stem cell aging [17]. Moderate intake of spermidine in diet can reduce blood pressure, prevent cardiovascular and cerebrovascular diseases, and reduce the risk of Alzheimer's disease and death [18]. Polyamines are beneficial to prevent aging-related diseases. Fermented natto is a good source of polyamines [19]. However, excessive intake can also cause some adverse reactions. In serious cases, it can also cause cerebral hemorrhage, even endanger our lives. Eating foods rich in tyramine, such as fish or fish products, can cause toxicological reactions, such as headache, migraine, neurological diseases, nausea, vomiting, respiratory diseases and hypertension [20]. Similarly, consumption of histamine-rich foods can cause gastrointestinal, circulatory and respiratory symptoms, flushing, rashes, urticarial and so on [21] [22]. The US Food and Drug Administration (FDA) recommends that the histamine safety 
threshold in fish is $500 \mathrm{mg} / \mathrm{kg}$ (Food and Drug Administration, 2001). In the process of natto fermentation, the total amount of biogenic amines is 26.47 $72.97 \mathrm{mg} / \mathrm{kg}$, which can't threaten our body considering the dosage [23]. The content of tyramine with direct toxicity to human body is only between 18.1 $22.3 \mathrm{mg} / \mathrm{kg}$, which is far lower than the limit standard of $100-800 \mathrm{mg} / \mathrm{kg}$ according to the limit standard of European Food Safety Authority (EFSA) and FDA. Spermidine is cytotoxic, but the current research results show that the toxic concentration of spermidine is higher than the maximum concentration found in food, so the view that spermidine or spermidine in food is harmful to health hasn't enough proof at present [24] [25]. The research result shows that any kind of substance in food necessary for the body must keep a certain balance. The formation of polyamines is related to soybean materials, but less to Bacillus subtilis [19].

\subsubsection{Natto Bacillus subtilis}

After eating Natto, Bacillus subtilis can live and proliferate in the intestine for several weeks, secrete a variety of enzymes and vitamins to promote the proliferation of intestinal mucosal cells. The cellulose materials of natto Bacillus subtilis can be coupled with oligosaccharides to promote the proliferation of Bifidobacterium [15] [26]. Natto Bacillus subtilis can inhibit spoilage microorganisms that cause abnormal fermentation in the intestine, and prevent diarrhea, dysentery, enteritis and constipation. As a whole, it plays an important role in regulating the microecological balance of intestinal flora. Mucus of natto covering the surface of gastrointestinal mucosa can protect the gastrointestinal system and alleviate drunkenness when drinking alcohol.

\section{Prospects of Natto}

With the trade dispute between China and the United States, the cost of imported soybeans has increased, which has greatly impacted the related domestic industries. This also urges us to change our minds and improve the added value of soybean. Natto is facing such a powerful opportunity. Natto is a kind of functional food with low cost and rich nutrition, which should be developed and promoted vigorously.

However, natto cannot be accepted by most people in our country because of its special smell. There are three sources of flavor. First, ammonia odor is produced when natto bacteria decompose protein during fermentation. Second, the branched chain amino acids (valine, leucine and isoleucine) generate $\alpha$-keto acids under the catalysis of dehydrogenase, then form aldehydes under the catalysis of $\alpha$-keto acid decarboxylase, and then generate branched-chain short fatty acids (BCFAs) under the catalysis of aldehyde deaminase. BCFAs is an uncomfortable taste in natto [27]. In addition, there is another way, the branched chain amino acids generate $\alpha$-keto acid under the catalysis of dehydrogenase, and then form acyl-CoA under the catalysis of $\alpha$-keto acid deaminase complex, and then generate BCFAs under the catalysis of phosphotransbutyrylase (PTB). Third, in 
the process of protein decomposition, some bitter peptides will be produced to make natto bitter. Although bitter peptides have some health care functions, but as a kind of food, bitter peptides are unpopular and unaccepted.

Therefore, we should take various methods to improve the flavor of natto. First, its flavor can be improved by physical methods, making natto into natto ice cream, natto sushi, natto porridge, natto pickled vegetable, to some extent to eliminate some undesirable smell. At present, we have also tried some effective methods, for example, to make garlic natto, sauce natto, fruit natto, milk natto, yogurt natoo, etc. Second, we can control the fermentation process to improve the flavor. The fermentation process should not be more than 24 hours, because the time is too long, the activity of natto bacteria will decline, and then a large number of bacteria will die, which will produce a strong ammonia odor. Another way is the fermentation substrate can be changed into small soybean or peeled mung beans to improve the flavor of natto. Meanwhile, the storage time of natto should not be too long, otherwise, the taste will be heavier. Third, through genetic engineering, we can regulate the expression of key genes in the metabolic pathway of odor production to achieve the regulation of flavor. As we mentioned above, PTB gene is considered to be the key gene of BCFAs synthesis. The ammonia odor can be reduced by regulating down the expression of PTB gene [27]. Through the exploration and practice in life, we can effectively improve the flavor of natto and make it become a good healthy product for everyone.

Except for the flavor of natto, we should also pay attention to the standardization of natto, the propaganda and the guidance of national policy in order to deepen the natto industry.

In a word, these functional components of natto could contribute to improving human health as well as increasing the high-quality life especially for the elderly. We hope natto would gain popularity as a health food throughout the world.

\section{Funded Projects}

Soybean post-harvest service and processing funded projects of modern agricultural industrial technology system in Hebei Province (326-0702-JSNTKSF).

\section{Conflicts of Interest}

The authors declare no conflicts of interest regarding the publication of this paper.

\section{References}

[1] Nagata, C., Wada, K., Tamura, T., Konishi, K., Goto, Y., Koda, S., Kawachi, T., Tsuji, M. and Nakamura, K. (2017) Dietary Soy and Natto Intake and Cardiovascular Disease Mortality in Japanese Adults: The Takayama Study. The American Journal of Clinical Nutrition, 105, 426-431. https://doi.org/10.3945/ajcn.116.137281

[2] Weng, Y., Yao, J., Sparks, S. and Wang, K.Y. (2017) Nattokinase: An Oral Antithrombotic Agent for the Prevention of Cardiovascular Disease. International Journal 
of Molecular Sciences, 18, 523-535. https://doi.org/10.3390/ijms18030523

[3] Fujita, M., Ohnishi, K., Takaoka, S., Ogasawara, K., Fukuyama, R. and Nakamuta, H. (2011) Antihypertensive Effects of Continuous Oral Administration of Nattokinase and Its Fragments in Spontaneously Hypertensive Rats. Biological and Pharmaceutical Bulletin, 34, 1696-1701. https://doi.org/10.1248/bpb.34.1696

[4] Liu, J., Chang, S.K. and Wiesenborn, D. (2005) Antioxidant Properties of Soybean Isoflavone Extract and Tofu in Vitro and in Vivo. Journal of Agricultural and Food Chemistry, 53, 2333-2340. https://doi.org/10.1021/jf048552e

[5] Chang, Y.Y., Liu, J.S., Lai, S.L., Wu, H.S. and Lan, M.Y. (2008) Cerebellar Hemorrhage Provoked by Combined Use of Nattokinase and Aspirin in a Patient with Cerebral Microbleeds. Internal Medicine Journal, 47, 467-469. https://doi.org/10.2169/internalmedicine.47.0620

[6] Fadl, N.N., Ahmed, H.H., Booles, H.F. and Sayed, A.H. (2013) Serrapeptase and Nattokinase Intervention for Relieving Alzheimer's Disease Pathophysiology in Rat Model. Human \& Experimental Toxicology, 32, 721-735.

https://doi.org/10.1177/0960327112467040

[7] Dogné, J.M., Hanson, J., de Leval, X., Pratico, D., Pace-Asciak, C.R., Drion, P., Pirotte, B. and Ruan, K.H. (2006) From the Design to the Clinical Application of Thromboxane Modulators . Current Pharmaceutical Design, 12, 903-923. https://doi.org/10.2174/138161206776055921

[8] Yang, Y., Lai, X.Y., Wang, P.F. and Liao, E.Y. (2008) Matrix GLA Protein and Postmenopausal Osteoporosis. Chinese Journal of Osteoporosis, 11, 839-841.

[9] Sumi, H., Hamada, H., Tsushima, H., Mihara, H. and Muraki, H. (1987) A Novel Fibrinolytic Enzyme (Nattokinase) in the Vegetable Cheese Natto; a Typical and Popular Soybean Food in the Japanese Diet. Experientia, 43, 1110-1111. https://doi.org/10.1007/BF01956052

[10] Fujita, M., Nomura, K., Hong, K., Ito, Y., Asada, A. and Nishimuro, S. (1993) Purification and Characterization of a Strong Fibrinolytic Enzyme (Nattokinase) in the Vegetable Cheese Natto, a Popular Soybean Fermented Food in Japan. Biochemical and Biophysical Research Communications, 197, 1340-1347.

https://doi.org/10.1006/bbrc.1993.2624

[11] Sumi, H., Hamada, H., Nakanishi, K. and Hiratani, H. (1990) Enhancement of the Fibrinolytic Activity in Plasma by Oral Administration of Nattokinase. Acta Haematologica, 84, 139-143. https://doi.org/10.1159/000205051

[12] Setchell, K.D., Brown, N.M. and Lydeking-Olsen, E. (2002) The Clinical Importance of the Metabolite Equol-A Clue to the Effectiveness of Soy and Its Isoflavones. The Journal of Nutrition, 132, 3577-3584. https://doi.org/10.1093/jn/132.12.3577

[13] Patel, R.P., Boersma, B.J., Crawford, J.H., Hogg, N., Kirk, M., Kalyanaraman, B., Parks, D.A., Barnes, S. and Darley-Usmar, V. (2001) Antioxidant Mechanisms of Isoflavones in Lipid Systems: Paradoxical Effects of Peroxyl Radical Scavenging. Free Radical Biology and Medicine, 31, 1570-1581. https://doi.org/10.1016/S0891-5849(01)00737-7

[14] Zaheer, K. and Humayoun, A.M. (2017) An Updated Review of Dietary Isoflavones: Nutrition, Processing, Bioavailability and Impacts on Human Health. Critical Reviews in Food Science and Nutrition, 57, 1280-1293. https://doi.org/10.1080/10408398.2014.989958

[15] Bhat, A.R., Irorere, V.U., Bartlett, T., Hill, D., Kedia, G., Morris, M.R., Charalampopoulos, D. and Radecka, I. (2013) Bacillus Subtilis Natto: A Non-Toxic Source of Poly- $\gamma$-Glutamic Acid That Could Be Used as a Cryoprotectant for Probiotic Bacte- 
ria. AMB Express, 3, Article No. 36. https://doi.org/10.1186/2191-0855-3-36

[16] Li, Q.L. (2019) Establishment of in Vivo Evaluation System and Product Quality Evaluation of the Fermented Soybeans by Endophytic Bacteria Isolated from Soybeans. Master's thesis, Hebei Agricultural University, China.

[17] Madeo, F., Eisenberg, T., Pietrocola, F. and Kroemer, G. (2018) Spermidine in Health and Disease. Science, 359, 410-421. https://doi.org/10.1126/science.aan2788

[18] Eisenberg, T., Abdellatif, M., Zimmermann. A., Schroeder, S., Pendl, T., Harger, A., Stekovic, S., Schipke, J., Magnes, C., Schmidt, A., Ruckenstuhl, C., Dammbrueck, C., Gross, A.S., Herbst, V., Carmona-Gutierrez, D., Pietrocola, F., Pieber, T.R., Sigrist, S.J., Linke, W.A., Mühlfeld, C., Sadoshima, J., Dengjel, J., Kiechl, S., Kroemer, G., Sedej, S., Madeo, F. (2017) Dietary Spermidine for Lowering High Blood Pressure. Autophagy, 13, 767-769. https://doi.org/10.1080/15548627.2017.1280225

[19] Kobayashi, K., Horii, Y., Watanabe, S., Kubo, Y., Koguchi, K., Hoshi, Y., Matsumoto, K.I. and Soda, K. (2017) Comparison of Soybean Cultivars for Enhancement of the Polyamine Contents in the Fermented Soybean Natto Using Bacillus subtilis (Natto). Bioscience, Biotechnology and Biochemistry, 81, 587-594.

https://doi.org/10.1080/09168451.2016.1270738

[20] Shalaby, A.R. (1996) Significance of Biogenic Amines to Food Safety and Human Health. Food Research International, 29, 675-690. https://doi.org/10.1016/S0963-9969(96)00066-X

[21] Ladero, V., Calles-Enríquez, M., Fernández, M. and Alvarez, M.A. (2010) Toxicological Effects of Dietary Biogenic Amines. Current Nutrition and Food Science, 6, 145-156. https://doi.org/10.2174/157340110791233256

[22] Visciano, P., Schirone, M., Tofalo, R. and Suzzi, G. (2014) Histamine Poisoning and Control Measures in Fish and Fishery Products. Frontiers in Microbiology, 5, 1-3. https://doi.org/10.3389/fmicb.2014.00500

[23] Gao, Z.X., He, L.P., Liu, Y.B., Gao, B., Li, C.Q. and Liu, H.Y. (2018) Screening of a High-Yield Nattokinase-Producing Strain and Changes of Biogenic Amines during Natto Fermentation. Food Science, 39, 185-191.

[24] Del, R.B., Redruello, B., Linares, D.M., Ladero, V., Fernandez, M., Martin, M.C., Ruas-Madiedo, P. and Alvarez, M.A. (2017) The Dietary Biogenic Amines Tyramine and Histamine Show Synergistic Toxicity towards Intestinal Cells in Culture. Food Chemistry, 218, 249-255. https://doi.org/10.1016/j.foodchem.2016.09.046

[25] Del, R.B., Redruello, B., Linares, D.M., Ladero, V., Ruas-Madiedo, P., Fernandez, M., Martin, M.C. and Alvarez, M.A. (2018) Spermine and Spermidine Are Cytotoxic towards Intestinal Cellcultures, but Are They a Health Hazard at Concentrations Found In foods. Food Chemistry, 269, 321-326. https://doi.org/10.1016/j.foodchem.2018.06.148

[26] Song, D.J., Kang, H.Y., Wang, J.Q., Peng, H. and Bu, D.P. (2014) Effect of Feeding Bacillus subtilis Natto on Hindgut Fermentation and Microbiota of Holstein Dairy Cows. Asian-Australasian Journal of Animal Sciences, 27, 495-502. https://doi.org/10.5713/ajas.2013.13522

[27] Hong, C., Chen, Y., Li, L., Chen, S. and Wei, X. (2017) Identification of a Key Gene Involved in Branched-Chain Short Fatty Acids Formation in Natto by Transcriptional Analysis and Enzymatic Characterization in Bacillus subtilis. Journal of Agricultural and Food Chemistry, 65, 1592-1597. https://doi.org/10.1021/acs.jafc.6b05518 